\title{
The Challenge of Global Catastrophic Biological Risks
}

\author{
Nancy D. Connell
}

G lobal Catastrophic biological risks (GCBRs) are defined by the Johns Hopkins Center for Health Security as biological events-deliberate, accidental, or emerging - that "could lead to sudden, extraordinary, widespread disaster." There are a number of efforts to create a framework within which we can begin to address the almost incomprehensible consequences of these kinds of events. GCBRs comprise a specific subset of global catastrophic risks. The Global Priorities Project and the Future of Humanities Institute, in their joint report entitled Global Catastrophic Risks 2016, categorize global catastrophesevents or processes ending the lives of $10 \%$ of the population-into 2 categories: ongoing risks that could have an impact on the world at any time (eg, nuclear war and natural pandemics), and emerging risks that are unlikely now but are increasingly possible (eg, catastrophic climate change and emerging technologies). The GCBRs include both ongoing and emerging risks and have their roots in biological agents or processes.

I propose that analysis of potentially catastrophic events that were averted or mitigated might bring to light some of the approaches we can use to respond to or prepare for a global catastrophic biological event. The SARS outbreak of 2003 and the widespread Ebola outbreak of 2014-2016 are examples of near epidemics that were contained by a combination of international cooperation and basic research. There was major loss of life (particularly with Ebola virus infection) and extensive social disruption that crossed borders and extended to countries with few or no cases. The features of contemporary life and culture that contribute to the swift movement of infectious disease agents across the globe, such as rapid air travel and commerce, are the same components that permit a swift response to outbreaks: communications, rapid transport of logistical assistance, and the like. With each consequential outbreak, new parameters are set and studied-population density, animal control, transmissibility and susceptibility studies, antibiotic resistance, vaccine development, surveillance considerations - and the response communities, local, national and regional, have additional and iterative tools to deal with the next outbreak.

The Cuban missile crisis of 1962 led us dangerously close to initiating a nuclear war and stands as a warning of how close the world came to a catastrophic nuclear event in the last century. In fact, in a remarkable story, a man named Vasili Arkhipov single-handedly averted the firing of a nuclear torpedo at a US destroyer off the coast of Cuba. The consent of 3 Soviet officers was required to launch the torpedo; Arkhipov refused, citing the need for definitive proof that war had erupted at the surface. Thus, the moral strength and strategic foresight of a single person prevented WWIII.

I would argue that decisions to move forward with certain kinds of research projects-for example, genetic manipulation of germlines, creation of genetic chimeras, or development of superhuman capabilities — should continue to be extensively analyzed and debated in the global research arena until there is actual consensus on the moral baseline for these research tracks. As an example, after decades of debate, we have established international consensus on the issue of human subject protection; we can and should come to similar agreements over emerging genetic technologies.

Threaded throughout any discussion of emerging technologies and their influence on the probability of a global catastrophic biological event should be the interrelated concepts of safety and responsibility in the laboratory. Decreasing the likelihood of both accidental and intentional release of engineered pathogens requires the development of global, standardized safety and security cultures.

(C) Nancy D. Connell, 2017; Published by Mary Ann Liebert, Inc. This Open Access article is distributed under the terms of the Creative Commons Attribution Noncommercial License (http://creativecommons.org/licenses/by-nc/4.0/) which permits any noncommercial use, distribution, and reproduction in any medium, provided the original author(s) and the source are credited. 
Emerging technologies bring us closer to creative solutions to the world's pressing problems: food shortages, climate change, infectious disease. What are scientists' responsibilities in the successful regulation of these powerful new methodologies? Global cooperation among scientists_-including emphasis on the responsible conduct of scientific activities-will go a long way to developing a standard of biorisk management. Combining biosafety, biosecurity, and bioethics will help lead to an international "web of prevention."
Nancy D. Connell, PhD Professor and Director for Research Division of Infectious Disease Department of Medicine Rutgers New Jersey Medical School Medical Science Building (MSB) 185 South Orange Ave., Room A906 Newark, NJ 07101

Email: connell@njms.rutgers.edu 